\title{
My Theory of the Oxidative-deoxidative Imbalance in life value
}

\author{
Yan Wang* \\ American Physiological Society, USA
}

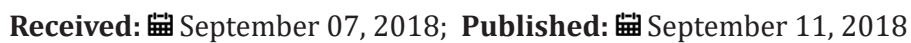

*Corresponding author: Yan Wang, American Physiological Society, Room 1101 Cell 2699 JinHe Rd. PuDong, Shanghai, China 200127

\section{Editorial}

I have words the imbalance of the oxidative-deoxidative state of a special substance happen at it is original prefect balance, the words can use to define my theory of the oxidative-deoxidative Imbalance in life value. I have first time to use the word in 2004 at my working speeches at the University of Pennsylvania School of Medicine. The oxidative state means the Reactive oxygen species (ROS) and reactive nitrogen species (RNS) generation with over producing over the deoxidative state in body, also toxic reagents as paraquat and $\mathrm{H}_{2} \mathrm{O}_{2}$ can induce oxidative stress. In traditional, ROS generation as $\left(\mathrm{OH}, \mathrm{O}_{2}^{-}, \mathrm{ROO}, \mathrm{RO}\right)$ have critical role in oxidative stress, then combined RNS generation as (ONOO, RSNO) can make the oxidative stress in whole meaning at ROS/ RNS induction to interrupt damage DNA construct, cell, lipids, proteins and other macromolecules. In biological state, ROS or RNS are generate in natural to take some important roles at cell signaling and homeostasis functional; under oxidative interruption, over products from endogenous and exogeneous detect deoxidative defend state to maintain balance of the two sides.

The deoxidative defense state have the enzyme system, nonenzyme system, small molecular (GSH) or more formed, then antioxidant enzyme as SOD, catalase, peroxidase defend oxidative stress through degradation ROS/RNS to nontoxic chemical [1] by the biochemical cycle in the goal to maintain the balance of oxidative generation and antioxidative defense for biology functional normal, it is in physiopathology protection from imbalance situation as Figure 1 presentation. Thinking of my theory in life value, I should analyze the meaning from the original recognition on the side of oxidative state inducing biofunction degradation and age older, with deoxidative state which can enhanced life value, delay life aging and maintain younger physiological states. The related labeled antioxidative products as SOD or vitamin C, E in pharmacy have been supplied and benefit peoples. In clinical observation, the disease mechanism for acute lung injury is caused from over
ROS generation to result in an imbalance with antioxidant defenses pathways; the clinical investigation for pulmonary hypertension is related with Nitro oxide(NO) generation decreasing from the reaction of $\mathrm{NO}$ with $\mathrm{O}_{2}$ - superoxide to form RNS[2]. RNS may act together with ROS in one disease to damage cells and organ function. The other diseases as neonatal respiratory distress syndrome, asthma or cardiovascular diseases are related with oxidative and deoxidative imbalance mechanism to disease development $[3,4]$

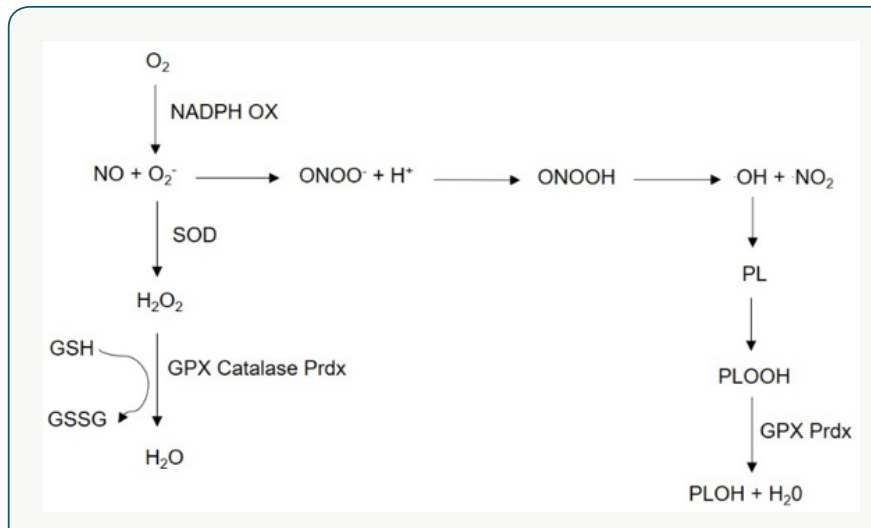

Figure 1: Oxidative stress and antioxidant enzymes biology pathway.

In my previous study on oxidative stress Biology, my project was on NO study with pulmonary hypertensive and respiratory failure, which was my $\mathrm{PhD}$ thesis at medical college FuDan University in Shanghai. My papers including about NO therapy with L-arginine to observe how L-arginine as the metabolic substrate of NO to affect NO and Endothelin (ET) in acute stress, the papers have published in China before 1999 while I left China to the United States of America as Medical Scholar at the University of Miami Medical School in 2000[2]. The recognized oxidative stress widely as a major pathophysiologic mechanism in various injuries that lead to either acute or chronic organ failure has developed in my research after 2000 when I have worked in the United States 
of America [4] Since then, I have studied antioxidant enzymes including SOD, catalase, peroxidase and GSH molecular. My projects have studied the antioxidant enzymes of peroxidases when I have worked at the University of Pennsylvania since 2002 to 2007. The study has used the modern methods from DNA clone, gene models, cell injury, protein-lipid oxidation and clinal disease to observation functional.

As I am special doctor is in emergency and pulmonary medicine, lung Biology have an example to explain my theory of the oxidative-deoxidative Imbalance in life value. Lung function disorder is tight related with oxidative stress over damaged; in clinical, it presents in respiratory difficult, edema Pulmonary aortic hypertension, inflammation reaction and function failure. My theory mechanism could take responsibility on explanation the situation. For other organs as cardiac or brain vascular system, oxidative and antioxidative imbalance also can induce more disorder in function and disease. Considering of oxidative and antioxidative states imbalance to medical biology in my theory, currently more important results on the studies have published in my articles and books at academic Journals in nations for attention the theory with human[5]. As usual knowledge, oxidative stress is one of the main reasons to result in degradation to human life span, studying in antioxidant defense system has activated goal to increase life value and qualify. However, who is worthy the value of longer life younger span, it also requires personal real perfect character and moral behavioral to improve physiological processing.

\section{Refrences}

1. Wang Y (2018) PRDX6 Antioxidative Enzyme at Oxidative Stress in Lung Biology, BAOJ Cellular \& Molecular Cardiology 4(1): 017.

2. Wang Y, Wang LB, Zhang LE (1997) L Arginine in the pathway of Nitric Oxide metabolism and respiratory diseases, Journal of Pediatric Emergency Medicine 4(1): 38-39.

3. Rhee SG, Chae HZ, Kim K (2005) Peroxiredoxins: a historical overview and speculative preview of novel mechanisms and emerging concepts in cell signaling. Free Radic Biol Med 38: 1543-1552.

4. Wang Y, Manevich Y, Feistein SI (2004) Adenovirus mediated transfer of the 1-cys peroxiredoxin gene to mouse lung protects against hyperoxic injury, American Journal of Physiology, Lung Cellular and Molecular Physiology 286: L1188-L1193.

5. Wang Y (2017) The Distance from Science to Common Life, EC Cardiology.

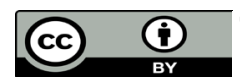

This work is licensed under Creative Commons Attribution 4.0 License

To Submit Your Article Click Here: Submit Article

DOI: $10.32474 /$ LOJMS.2018.01.000118

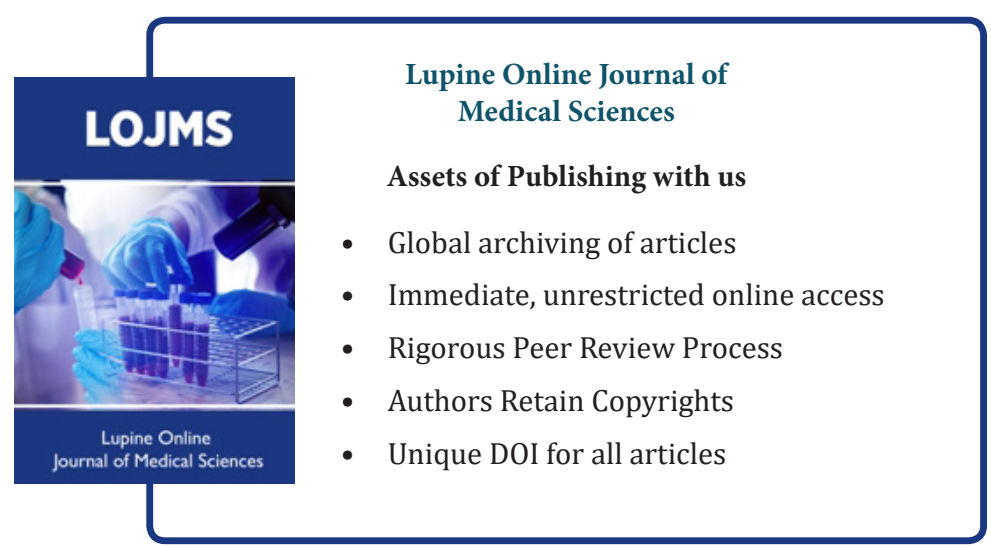

